\title{
The Counseling Psychologist
}

http://tcp.sagepub.com

\section{Self-Cultivation: Culturally Sensitive Psychotherapies in Confucian Societies \\ Kwang-Kuo Hwang and Jeffrey Chang \\ The Counseling Psychologist 2009; 37; 1010 \\ DOI: $10.1177 / 0011000009339976$}

The online version of this article can be found at:

http://cp.sagepub.com/cgi/content/abstract/37/7/1010

\section{Published by:}

\section{(3)SAGE}

http://www.sagepublications.com

On behalf of:

\section{$\Psi_{17}$}

Division of Counseling Psychology of the American Psychological Association

Additional services and information for The Counseling Psychologist can be found at:

Email Alerts: http://tcp.sagepub.com/cgi/alerts

Subscriptions: http://tcp.sagepub.com/subscriptions

Reprints: http://www.sagepub.com/journalsReprints.nav

Permissions: http://www.sagepub.com/journalsPermissions.nav

Citations http://tcp.sagepub.com/cgi/content/refs/37/7/1010 


\title{
Self-Cultivation
}

\section{Culturally Sensitive Psychotherapies in Confucian Societies $\Psi$}

\author{
Kwang-Kuo Hwang \\ National Taiwan University \\ Jeffrey Chang \\ Columbia University Teacher's College
}

\begin{abstract}
This article describes self-cultivation practices originating from the cultural traditions of Confucianism, Taoism, and Buddhism. It delineates the therapeutic implications of the three states of self pursued by these three traditions: namely, the relational self, the authentic self, and the nonself. Several psychotherapy techniques derived from each of these traditions are discussed in the context of contemporary Confucian societies in East Asia and North America. The indigenous approach to understanding psychotherapies within a cultural context may contribute to the training program of multicultural counseling psychology.
\end{abstract}

Keywords: self-cultivation; relational self; authentic self; nonself; multicultural psychology

$\mathrm{T}$ his article discusses the therapeutic functions of self-cultivation practices originating from the philosophies of Buddhism, Taoism, and Confucianism from the perspective of counseling psychology. Based on the presumption that the components of a cultural system can best be understood through their relationship with other components of the system, and therefore it should be explained in terms of the culture as a whole (Vygotskii, 1978), it is argued that the theories, objectives, and methods of mental health intervention are profoundly influenced by their sociocultural context and origins. A comprehensive understanding of the significant features of Confucian culture enables us to understand how the various traditional practices of self-cultivation may serve the function of psychotherapy for clients of East Asian descent (Chinese, Taiwanese, Japanese, and Korean) in both North America and East Asia.

$\Psi$ The Division 17 logo denotes that this article has been approved for continuing education credit. To access the CE test, please visit http://per-ce.net/ce/tcp.php. 
This article consists of four sections. The first addresses the goals of selfcultivation in Confucianism, Taoism, and Buddhism, which are, respectively, attaining a state of the relational self, authentic self, and nonself. Based on an analysis of the dynamic relationships between these three states of self and their therapeutic implications, the following three sections examine the psychotherapy practices derived from the cultural traditions of Confucianism, Taoism, and Buddhism.

\section{Goals of Self-Cultivation}

The term xiu-yang (self-cultivation) in Chinese is an abbreviation of xiuxin yang-xing, which literally means rectifying one's mind and nurturing one's character with a particular art or philosophy. Although this term applies to all three cultural traditions, the goals of self-cultivation and the state that each person should aspire to are completely different for Confucianism, Taoism, and Buddhism.

\section{Confucianism and the Relational Self}

According to Hwang's (2001a) analysis, Confucians advocated two kinds of ethics for ordinary people and scholars, respectively. Ordinary people are requested to practice Confucian ethics within their family, however the scholars are endowed with a mission to promote Confucian teachings not only within their family but also in the whole state.

Confucian ethics for ordinary people advocates the maintenance of interpersonal harmony by following the principle of respecting their superior (those above one in the hierarchy) and the principle of favoring the intimate (those with whom one has a blood relationship; Hwang, 2001a). Confucian cosmology emphasizes a simple fact that an individual's life is the continuation of one's parents' physical lives, just as their descendants' lives are derivatives of their own. Therefore, Confucians adhered to the core value of filial piety and advocated the ideal of "kind father and filial son" as a prototype for arranging the relationship between a "benevolent king and loyal minister" (Hwang, 1999).

In the Confucian model, parents are obligated to show kindness by taking good care of their children while children are expected to fulfill their filial duties by working hard to pursue the goals that are highly valued by the whole society. Children in a Confucian society are generally educated to have the discipline to cultivate themselves to be morally upright by 
following the rules of proper conduct ( $l i)$ and working hard to strive for socially approved goals (Bell \& Ham, 2003; Tu, 1976).

In contrast to the Western-style culture of self-contained individualism in which human rights and free choice are emphasized with the belief that there should be a clear-cut boundary between one's self and others (Sampson, 1988), Confucians advocate a kind of self-ensembled individualism in which a person is seen as embedded in a particular social network and the boundary of the self may be extended to include significant others (Hwang, 2001b). That is, instead of encouraging a child to have an independent self that is the autonomous agent of action, Confucian cultures tend to foster the individual's interdependent self (Markus \& Kitayama, 1991) or relational self (Chen, this issue). Confucian cultures foster the notion that each member of a dyadic relationship should take into consideration the other's expectations. Individuals are expected to fulfill role obligations in relationships, particularly to family members.

\section{Taoism and the Authentic Self}

Assuming one's role obligation in Confucian culture, where the principle of respecting the superior is emphasized, it may imply a kind of psychological burden caused by social restraint, interpersonal conflict, emotional disturbance, or frustration. In contrast to Confucianism, Taoism advocates self-cultivation as a source of healing and seeks to emancipate one's self from the ethical bounds of this world by following the way of Nature and returning to a state of authentic self-just like a newborn baby (Munro, 1985).

The cosmology of Taoism suggests that every element in every system of the universe is composed of two opposing components, yin and yang. These two components are kept in balance by the operation of $q i$ (氣; De Groot, 1912). Elements of all systems in the universe are believed to correspond to the Five Transformative Phases: metal, wood, water, fire, and earth. The fundamental operating rule of the world is seeking of harmonious equilibrium between humans and nature, humans and society, and within each human being (Kohn, 2004). Based on this philosophy, Taoists developed geomancy (feng-shui), a theory of fate, a system of Chinese medicine, and a theory of life and death.

Those systems of knowledge provide an interpretative system to explain an individual's fortune or misfortune in terms of that person's birth date (destiny): for instance, the specific arrangement of that person's home or ancestors' graves that is supposed to influence one's fortune (geomancy) (Spear, 1995; Wong, 1996), that person's ancestors (belief in soul), or the internal balance within that person's own body (concept of body). Any 
individual who seeks help or instruction from a fortune teller, a geomancer, a Taoist priest, or a Chinese medical doctor is encouraged to follow Way of the Nature with a clear vision of the authentic self, which should not be contaminated by one's personal desires.

\section{Buddhism and the Nonself}

The eternal goal of self-cultivation for Buddhists is nirvana, a state of nonself, which can be attained in two ways: by leaving home to become a monk or a nun or by staying at home and cultivating oneself to become a secular Buddhist devotee (jiu-shi). Whether one leaves or stays at home, the fundamental principle of self-cultivation for Buddhists is learning an attitude of detachment from this world, particularly detachment from a state of egoism, or holding on to one's self-concept, which is termed as atam-graha. In contrast to the tremendous effort to understand one's self by self-analysis or self-clarification in Western psychotherapy, Buddhism advocates a state of anatman or nonself in which the existence of self is as clear as crystal without any hindrance in one's mind (Fu \& Wawrytko, 1991, 1994). To attain this state, Buddhists must cultivate themselves by severing all ties to the world and giving their possessions to those who are in need of them.

During their history of evolution, Confucianism, Taoism, and Buddhism have adopted parts of doctrine from one another to form new branches and sects. Some of them had been disseminated to neighboring Asian areas including Taiwan, Japan, and Korea, where the same process of amalgamation and synthesis happened again and again. A new religion's sect is usually established by a master who has immersed himself or herself in the doctrine of that religion for a long period of time. Masters have cultivated themselves by practicing the commandments so as to attract a group of disciples to follow the same practices.

Similarly, when a professional psychologist finds that some traditional wisdom might be helpful for an individual to alleviate one's psychological sufferings in daily life, he or she may attempt to establish a new school of psychotherapy by utilizing all the possible resources from his or her cultural heritages. In this case, if the psychologist might play the role of master in East Asian culture, he or she must be familiar with various types of psychological disturbances that might be encountered by ordinary people in the society. When a client comes to him or her for help, he or she must be able to comprehend the client's problem with sympathetic understanding and give the most appropriate instruction for the client to follow while the client has to cultivate himself or herself with the wisdom provided by the psychologist. 
The goal of psychotherapy (or counseling) is to help the client to solve his or her problem (Heppner, 2006). The therapist (or counselor) has to utilize all the possible means to attain this pragmatic goal. Consequently, all resources of available cultural heritages might be utilized and combined to attain goals of self-cultivation in East Asian culture, namely, relational self, authentic self, or nonself.

\section{Action in Coordination With Others-In-Relation}

\section{Morita Therapy}

In the 1920s, Japanese therapist S. Morita (1874-1938) first tried to use the traditional Zen practice to help the client to alleviate the anxiety-based disorder shinkeishitsu and to take constructive action in social situations.

The goals of Morita therapy are the recognition of facts, obedience to nature, focus on the present, the increase of spontaneous activities, the decrease of self-focused preoccupation, the elimination of indulgence in moods and emotions (kibun honi), the withholding of value judgments, the reduction of intellectualizing, the cessation of escape into a sick role, and the cultivation of a humble (sunao) mind (Iwai \& Abe, 1975). Morita was interested in eliminating contradiction in ideas and fostering acceptance of facts in a state of arugamama, which means accepting things as they are. Morita postulated that this would be made possible by teaching clients in complete social isolation.

The prototypical form of Morita therapy is an inpatient treatment involving four stages: (a) isolation-rest therapy, (b) light occupational therapy, (c) heavy occupational therapy, and (d) complicated activity therapy in preparation for actual life. In the first stage, the therapist gives detailed explanations of the functions of anxiety symptoms, which cannot be treated by intellect.

For 7 days, clients are placed in complete isolation and told to maintain a resting or prone state except during use of the toilet and bath. Clients are instructed to observe their fears and anxieties without escaping. They would ideally become the focal points of subjective fears, without opportunities for escape or avoidance. This reflects a strong Zen influence. Morita rejected mind-body dualism and considered the "mind" to be of a fleeting nature whose "dynamic flow changes between external events and the self" (Morita, 1928/1998, p. 9). Morita therapy aimed for the development of mushoju shin,

a Zen term used to describe the state of alertness and mindfulness, without 
the narrowly self-focused attention at a particular bodily sensation, such as heart palpitations.

The second stage is designed to stimulate clients' spontaneous mental activities and desires for action. From the 2nd day of the second stage, clients learn to enact behaviors without self-preoccupation; they are directed to constant activities and permitted to engage in heavier and increasingly diversified work for more than 15 hours a day (Morita, 1928/1998). Clients are encouraged to keep a diary. Therapists read clients' diaries to assess their mental states and attitudes toward therapy. They write brief comments to guide clients but neither reinforce clients' complaints of anxiety symptoms nor impose large tasks on clients to prevent them from being overwhelmed by the desire for success and perfection. At the end of the second stage, clients generally stop complaining about their symptoms.

The goals of the third stage, which lasts 1 or 2 weeks, are to acquire patience and endure work, increase self-confidence, and provide encouragement through repeated experiences of success. Clients engage in various tasks such as mopping the floor or washing dishes. Through the direct experience of successfully executed tasks, clients are expected to learn the value of taking action before being preoccupied with anxiety symptoms.

The purpose of the fourth and final stage is to train clients to changes in the outside world. Purpose-oriented activities are emphasized. At this stage, clients are trained to act free of preoccupations and fixations. Therapists encourage clients to read as much as they can throughout the day. They are permitted to go outside the hospital for errands and experience the demands of the outside world, without anticipatory fears and preoccupations with anxiety symptoms.

The methods Morita therapists use vary. In Japan, there is often a period of isolated bed rest before the patient is exposed to counseling, instruction, and work therapy. In the United States, inpatient Morita therapy is generally unavailable, and most practitioners favor a counseling or educational approach, the emphasis of which is on developing healthy living skills, learning to work attentively, and taking steps to accomplish tasks and goals. For this reason, Morita therapy is sometimes referred to as the psychology of action.

\section{Naikan Therapy}

Naikan is a Japanese word meaning inside looking or introspection. A more poetic translation is seeing oneself with the mind's eye. It is a structured method of self-reflection that helps people to understand themselves, 
their relationships, and the fundamental nature of human existence. According to Naikan therapy, an individual's psychological problems are rooted in distorted interpersonal relationships with significant others (Kimura, 1972).

Naikan therapy is concerned with procedures of directed client selfexamination. Clients are given sets of individual instructions. The three crucial instructions are: (a) Recall and examine your memories on care and benevolence you have received from a particular person, (b) recollect and examine your memories on what you have returned to that person, and (c) recollect and examine trouble and worries you have given to that person (Murase \& Johnson, 1974). Regardless of the clients' particular presenting problems, the instructions are entirely concerned with specific interpersonal relationships.

The first subject of Naikan therapy is usually clients' relationships with their mothers. The therapist instructs clients to recall and examine specific detailed life events that involved them and their mothers, from when they were in elementary school chronologically to the present. The clients sit in an isolated place and actively review their past lives for several hours continuously on single themes of interpersonal obligations and exchanges. A person is regarded as weak and guilty, and the realization of one's guilt, defined in terms of the therapist's three specific instructions, is itself an educational experience. There is a strong social factor in the self-illumination of Japanese people.

Based on the three questions of what the client has received, given, and the difficulties caused for others, Naikan therapy provides a foundation for reflecting on relationships with others. In each case, the clinician and the client search for a more realistic view of conduct and of the give-and-take that has occurred in relationships.

Comparing Morita therapy and Naikan therapy with Chen's (2009) model of self-relation condition, it can be seen that all three of them are concerned with attaining the goal of being a relational self, who is able to take actions in coordination with others-in-relation, while maintaining a state of psychosocial homeostasis (Hsu, 1971). Morita therapy adopted the Zen practice of nonself as a mean to help the client to return to realistic social world, whereas Naikan therapy and Chen's model of self-relational condition urge the client to reflect on their interpersonal relationships directly. Both of them recognized that positive interpersonal bonds are developed and maintained by the mutual fulfillment of obligations within a hierarchical and collectivistic societal structure. Morita therapy and Naikan therapy had been developed in pre- and post-war Japan, respectively; 
Chen's model was developed in contemporary Taiwan. They represent a pragmatic principle of multicultural counseling, namely, attaining the goal of "action in appropriate relation with others in this world" by adequate cultural means available in a given social context. Let's examine its derivative in the United States.

\section{Constructive Living Therapy}

Striving for a culturally modified application of Morita and Naikan principles in the United States for English-speaking individuals, David Reynolds $(1976,1980,1983)$ studied Naikan and Morita therapies in Japan in the 1960s, conducted fieldwork in these methods for his doctoral dissertation in anthropology, and began to integrate common value of these two methods. He called the result constructive living therapy.

Constructive living therapy assumes that with the uncontrollability of feelings and emotional states, a client's energy should be logically redirected toward behavior and action. This redirection helps to ground the client in the reality of life, rather than remaining absorbed in life's emotional overtones. The purpose of therapy, and in fact of life, goes beyond feeling good or happy. Such feelings are often by-products of a healthy, meaningful existence, but they are not ends in themselves. Following this line of reasoning, constructive living methods reflect a diminished emphasis on talking and a greater focus on practice and experience. The three elements of constructive living are "accept reality, know your purpose, and do what needs to be done" (Reynolds, 1995, p. 21).

In the cognitive realm, Reynolds (1980) noted the importance of teaching a realistic acceptance of the way things are now in the present moment as a first step in making positive changes. He spoke explicitly of the importance of being "reality-centered" (Reynolds, 1990, p. 110). Struggling with immutable aspects of life is seen as self-defeating.

When clients stop struggling with the reality of their experiences, they become free to act sensibly and constructively to make positive changes in their immediate world (Reynolds, 1987). Behavior is viewed as being more controllable than feelings. Clients are responsible for their behavior. Behavior can indirectly influence feelings, but behavior is not responsible for their feelings. One's work and family responsibilities must be attended to in spite of the presence of various symptoms or unpleasant feelings. Each goal is broken down into specific required activities of the client and monitored by the therapist. The value for the client's organized life is highly valued. 
Reynolds (1987) maintained that social and moral errors play as much a role in neurosis as ordinarily conceived psychological problems. He believed that many neurotic problems can be ameliorated by correcting "sloppy and thoughtless acts" (Reynolds, 1987, p. 21). In constructive living, a neglect of the moral side of behavior has important psychological repercussions. The constructive living client is taught to effectively cope with what one is confronted with in daily situations, irrespective of immediate consequences reinforcing or punishing client behavior. Furthermore, an ideal outcome will result in behavioral attempts to repay the debt for what one has received from significant others and from society. These attempts can provide a new meaning to and a constructive sense of purpose in one's life. Reynolds (1989a) commented, "When the focus of attention shifts from personal misery to making steps toward repaying others, much neurotic suffering evaporates as constructive purpose enters a life. I've never met a neurotic person filled with gratitude" (p. 7).

Constructive living can be viewed as the Westernized version of Naikan therapy. According to Reynolds (1995), the focus of autonomy, expression, and satisfaction of the individual in Western therapies can stand in the way of clients learning the satisfaction of serving others. "One of the goals of Constructive Living is to shake the foundations of clinical psychology and psychiatry in the West" (p. 5).

\section{Taoist State of Authentic Self and Psychotherapy}

Confucian and Taoist philosophies are best seen as complementary opposites of Chinese indigenous psychology. In contrast to the interpersonal disturbance that a relational self may experience, Taoism proposes several mental and physical exercises that may help an individual to eliminate all spiritual and psychological contamination, including qigong (a traditional Chinese therapy of physical movement aimed to enhance one's inner strength by exercising and controlling one's own muscle and breathing; Cohen, 1997), taiqichuan (shadow boxing), and Taoist meditation (K. Y. Lu, 1964; Ni, 1992). By practicing these methods of self-cultivation, an individual may return to the state of authentic self in which that person moves with the rhythm of the universe, similarly to a fetus moving in a mother's womb.

Some scholars have tried to study the effects of mental and physical exercises originating from Taoism. For example, Kerr's (2002) study explored two conflicting models of how patients experience mind-body therapies. 
These models frame the design of a clinical trial examining the effects of qigong on the immune systems of former cancer patients. Data consist of ethnographic research and in-depth interviews conducted at the Boston teaching hospital where the trial took place. These interviews with biomedical researchers, who designed the trial, together with the qigong master, responsible for the qigong portion of the trial, revealed two fundamentally different understandings of how qigong is experienced and how that experience may be beneficial to clients.

The biomedical team saw qigong as a nonspecific therapy that combines relaxation and exercise. The qigong master on the other hand saw qigong as using specific movements and visualizations to direct mental attention to specific areas of the body. While the biomedical team framed qigong as a mind-body practice, the qigong master framed it as a mind-in-body practice in which one may control the rhythmic movements of one's body at the will of his or her authentic self.

\section{The Application of Tao-Te Ching}

Early before the practices of taiqichuan and qigong gained their popularity in Western world, Carl Jung (1875-1961) was the first scholar to incorporate many ideas of Taoism into his theory of psychotherapy. He wrote the foreword for the German translation of I Ching (The Book of Change; Wilhelm, 1960) and collaborated with Richard Wilhelm (1879-1930) to translate The Secret of the Golden Flower (T. P. Lu, 1962), a classic of Taoism, into German (Wilhelm, 1962).

The applied research of Ron Kurtz, who developed the Hakomi method of body-centered psychotherapy, and Greg Johanson, senior trainer at the Hakomi Institute, should be discussed here to illustrate the connection between the ancient principles of the Lao Tzu's Tao-Te Ching and modern psychotherapy. Written for both therapists and clients, Johanson and Kurtz's (1991) case study, anecdotal materials, and literature review addressed issues of nonviolence, the use of the body in therapy, the importance of mindfulness, and the interrelatedness of all things. The introduction suggested that the reader approach the book in a meditative way by openly acknowledging any sensation and using self-inquiry into the experience (Johanson \& Kurtz, 1991). Each chapter quotes various translations of the Tao-Te Ching. Case examples are given to show a way of practicing therapy that is congruent with the principles of the Tao-Te Ching and emphasize how Lao Tzu's wisdom can provide a foundation and framework for inventing whatever technique is useful in a particular moment. 
The following paragraphs discuss excerpts from Johansen and Kurtz's (1991) findings.

Williamson's (1992) supportive empirical and qualitative findings for the integration of Taoist techniques as portrayed in the Tao-Te Ching and empathic attunement (instead of insight delivered through interpretation) in Western self-psychological therapy, Hranilovich's (1991) dissertation applications of Tao-Te-Ching to psychotherapy theory and technique, and Doelger's (1978) systematic dissertation comparison of Perl's Gestalt therapy and Tao-Te-Ching all carry significant implications for psychotherapeutic success with people from Chinese cultures.

\section{Chinese Taoist Cognitive Psychotherapy}

Although various forms of Taoist self-cultivation have been widely practiced in China for hundreds of years, it is a recent event that there are a group of Chinese psychologists who have tried to develop it as a method of psychotherapy and to study its effects by the scientific method of Western psychology (Zhang et al., 2002). The Chinese Taoist cognitive psychotherapy (CTCP) combines elements of cognitive therapy and Taoist philosophy for contemporary Chinese clients to learn coping skills with their current work and social reality.

CTCP involves a total of 151 -hour sessions administered over 6 months. The CTCP model of intervention contains five sequential stages, which are sequentially conducted at 5 or more sessions of 1 hour each, depending on the client's need to repeat Stages D and E (Zhang et al., 2002). A careful assessment of the client's level of stress, hierarchy of needs, and conflict and coping styles is conducted from Stages A to C. After the first cycle of all five stages is completed, for the most part, Stages D and E are repeated.

In Stage A, the clinician assists clients in identifying and analyzing actual stressors based mostly on subjective experiences connected to their illness, rather than on an objective number of stressful events. In Stage B, clients are instructed to share their self-prioritized needs according to personal opinion instead of suiting mainstream societal norms on moral behavior. In Stage C, the relative effectiveness of the client's coping strategies is evaluated based on the client's indicated degree of use in the event of psychological conflict (Zhang, 1993). After a careful assessment of the client's level of stress, hierarchy of needs, and conflict and coping styles, the therapeutic core of CTCP in Stage D explains the complementary roles of Taoism and Confucianism prior to a discussion of the 32-character Taoist formula within the same Stage D. 
As described by Zhang et al. (2002, p. 128), the 32-character formula in Stage D is composed of four 8-character sentences that outline the central tenets of Taoism. (a) The first 8 characters from Chapter 22 of the Lao-Tzu form the sentence "Yi er bu hai, wei er bu zheng" and imply "benefiting without hurting others, acting without striving." (b) The second group of 8 characters from Chapters 41, 43, and 46 in the Lao-zi and Zhuang-zi Xio yao you form the sentence "Shao si gua yu, zhi zu zhi zhi" and involve "restricting selfish desires, learning to be content, and knowing how to let go." (c) The third set of 8 characters from Chapters 41, 43, and 78 in Lao-zi is the sentence "Zhi he chu xia, yi rou sheng gang," which means "being in harmony with others and being humble, using softness to defeat hardness." And (d) the fourth and last set of 8 form the sentence "Qing jing wu wi, ren qi zi ran." The latter sentence implies "maintaining tranquility, act less, and follow the laws of nature." Clients are helped to achieve a deep understanding of these philosophical tenets by studying Tao-Te Ching and to apply such principles as acceptance, detachment, tranquility, and conformity with the laws of nature as means of coping with psychosocial conflicts.

In Stage E, a comprehensive assessment of effectiveness is performed through the client's self-report and discussion of therapeutic experience and clinical rating scales.

As a measure of CTCP's clinical efficacy with clients, Zhang et al.'s (2002) longitudinal clinical study finds that Taoist values are helpful to clients with anxiety-related conditions, the most common form of mood condition in epidemiological and clinical studies in East Asian communities (S. Lee \& Kleinman, 1997). Zhang et al.'s study compared the efficacy of CTCP, benzodiazepines (BDZ), and combined treatment for patients in urban China with generalized anxiety disorder (GAD). In total, 143 patients with GAD were randomly assigned to one of three treatment groups: CTCP only, BDZ only, or combined CTCP and BDZ treatment. Patients were evaluated at intake and reexamined 1 and 6 months after treatment.

The results indicated that $\mathrm{BDZ}$ treatment rapidly reduced symptoms of GAD from the 1st to the 6th month, with CTCP significantly taking effect at 6 months of treatment to maintain client reduction of GAD symptoms. Combined treatment led to acute as well as enduring symptom reduction. Unlike BDZ treatment, CTCP reduced Type A behavior, improved coping style, and decreased neuroticism. It was concluded that CTCP with or without BDZ treatment is a more effective, although slower, method for the treatment of GAD than BDZ for GAD patients in urban China.

This result implies for practitioners that when intervening with Chinese clients, the entire scope of potential advantages and drawbacks of immediate 
relief versus a more gradual, culturally sensitive approach should be fully and clearly explained to the counseling client, and the client's final decision regarding treatment should be respected.

\section{Buddhist State of Nonself and Psychotherapy}

Since the end of World War II, clinical psychology has focused primarily on the diagnosis and treatment of mental disease, and only recently has scientific attention turned to understanding and cultivating positive mental health (Seligman \& Csikszentmihalyi, 2000). In contrast to this, for the past 2,500 years, the timeless message of Buddhist dharma has systematically identified and diagnosed the symptoms of human suffering, determined their cause, described cures for illnesses, and prescribed treatment to cultivate happiness and lasting contentment. The practical Buddhist teachings of love, understanding, tolerance, and impermanence are all applicable to modern life (E. Lee, 1997; Smith, 1991; Yeung, 1995).

Recently, an increasing number of clinicians have begun to explore the possibility of applying Buddhist principles and techniques in therapeutic contexts. In fact, some have already begun integrating indigenous healing practices and spirituality, such as Buddhism, into clients' treatment planning. For instance, in the New York City suburb of Queens, Kershaw (2003) cited the East Asian-American Family Clinic's mental health services to East Asian immigrants; the blending of Zen Buddhism, Confucianism, and psychotherapy in treatment; the use of antidepressants; and the impact of physical differences that make the treatment of East Asian patients different from Western patients, especially considering the occurrence of mental illnesses often referred to by the community as neurasthenia, or shenjinshuaruio in Mandarin. Three of the many approaches to apply Buddhist teachings in counseling are briefly outlined in the following.

\section{Practical Therapy}

Practical therapy is a behavioral approach that teaches people to take action to achieve mental harmony and stability. Intentional action emphasizes the need for daily perseverance and practice to achieve regularity (Gielen, Jeffersen, \& Juris, 2004).

Meditation is important in the practice of Buddhism. The ultimate goal of Buddhist meditation is liberation (nirvana) through enlightenment, or realizing the essential nature of nonself through the impermanency of this 
world. Ethical conduct is the first step toward this goal. It prepares one for meditative concentration leading to insight (Goleman, 1977). The Buddhist Five Moral Precepts are basic human virtues of mutual respect and the very essence of spiritual cultivation. Practicing the way of the bodhisattva means to refrain from killing, stealing, sexual misconduct, falsifying, and self-intoxication and leads to cessation of suffering. This practice implies that the person should devote the self to the practice of the doctrines of the Eightfold Path and the Six Perfections (E. Lee, 1997; Yeung, 1995).

The Eightfold Path essentially is a practical guideline in a highly interdependent relationship to ethical and mental development with the goal of freeing the individual from attachments and delusions; it ultimately leads to understanding the wisdom or truth about all things. Mental development consists of right effort, mindfulness, and concentration. Ethical conduct consists of right speech, action, and livelihood. Wisdom consists of right view and intention. The Six Perfections are generosity, morality, patience, vigor, meditation, and wisdom (Fu \& Wawrytko, 1991, 1994). The path to becoming a Boddhisatva, or a Buddha-to-be, incorporates the Six Perfections to develop the necessary morality, compassion, and wisdom for the sake of leading others to nirvana prior to serving the self.

\section{Meditation}

Buddhist meditation differs from Hindu modes of meditation in stressing mindfulness, awareness, vigilance, and observation in everyday life. By maintaining a wakeful attitude, one develops insight into the essential nature of things. This particular insight helps one to take on a detached and dispassionate view of things. One is not easily disturbed by petty annoyances or even major setbacks. One learns to live in the present and attend to the activity one is engaged in at the moment (Rahula, 1973). Goleman (1977) maintained that in spite of apparent differences in Hindu and Buddhist meditation procedures, different modes of meditation lead to the same result of an altered state of consciousness. This altered state of consciousness, called superconsciousness in Hindu meditation, is common to many Eastern and Western religious traditions (Ornstein, 1972).

Zen Buddhism is a major offshoot of the Mahayana tradition of Buddhism. Originating in China, it was later transplanted to Japan by two Japanese student monks. It emphasizes meditation and spiritual practices that are currently being used as a mode of psychotherapy in Japan (Reynolds, 1980). Zen masters use the techniques of mondo to bring about sudden illumination (satori). Mondo consists of asking pupils sudden questions to 
test their insight and posing riddles (koans) that are meant to break down logical trains of thought (e.g., What is the sound of one hand clapping?; Das, 1987).

Buddhist masters have developed many different meditation techniques. The most general and widely practiced technique is breathing meditation. It consists of consciously focusing one's attention on the breath and then observing the resulting bodily and mental processes. By slowing down our thought processes, focusing on the present moment, and banishing all enmity and ill will from the mind, Buddhist meditation helps one to be calm, relaxed, and peaceful (Hahn, 1992). Meditation techniques, such as mindfulness and walking meditation, are also very useful in coping with negative emotions (Hahn, 1992). However, those with psychotic symptoms such as hallucinations should not meditate without close supervision (E. Lee, 1997; Yeung, 1995). Epstein (1995) explained the unique psychological contributions of Buddhist teachings, described the usage of meditation in contemporary psychological vernacular, and laid the foundation for a meditation-inspired psychotherapy.

There are several hypotheses regarding the beneficial effects of meditation; for example, that one deliberately directs attention to the aspects of the immediate surrounding environment, within which one is likely to act spontaneously in daily living. This is followed by attempts to perform these actions less impulsively and more mindfully. This process is called deautomization (Deikman, 1982). Another hypothesis with some empirical support is that meditation produces a hypometabolic state opposite to the fight or flight emergency response by lowering the activity of the sympathetic nervous system and protecting the body from the adverse effects of stress (R. K. Wallace \& Benson, 1972).

Although not all of its benefits are consistently repeatable, empirical studies have indicated that the physiological and psychological effects of Zen meditation are similar to those of yoga and transcendental meditation (R. K. Wallace \& Benson, 1972): namely, improved vitality, freedom from chronic disease, reduced anxiety and other neurotic symptoms, increased self-control, greater work efficiency, deeper understanding of the interdependence of all in the universe, and an enhanced sense of compassion (Sato, 1968).

Use of meditation in conjunction with psychotherapy has been found to produce the desirable effects of tension reduction, increased physical stamina, lessened tendency for self-blame, mood stabilization, an increased sense of affective relatedness with others, an increased sense of separate identity, and a reduced tendency for drug abuse (Carrington \& Ephron, 1976; Kutz, Borysenko, \& Benson, 1985). 
Davidson and colleagues (2003) found that novice meditation practice was associated with significantly greater activity in the left prefrontal cortex, an area of the brain associated with positive emotion. This finding was further supported by a prospective randomized controlled trial by examining the effects of mindfulness meditation on brain activity as well as psychological and immunological functioning.

\section{Conceptual Therapy}

This cognitive approach to therapy is based on the Buddhist principle that all of existence is a creation of the mind. Enlightenment, based on the nature of the nonself through a realization about the impermanency of the physical self, may detach an individual from all kinds of suffering in order to stay in an internal state of calm and joyfulness. People can gradually learn and change their way of thinking, feeling, and acting from negative dissonance to positive mental harmony to attain therapeutic goals. The clinician is strongly encouraged to study recent, real-world case examples that illustrate successful application of conceptual therapy through specific Buddhist principles, such as the concepts of eight sufferings and impermanence, birth and death, cause and effect, and nonself and illusion (E. Lee, 1997; Yeung, 1995).

Storytelling can be used effectively to enhance the client's understanding of a specific situation. Many Buddhist stories can be applied in counseling sessions (E. Lee, 1997; Yeung, 1995). For instance, the following story is frequently used to demonstrate the concept of letting go and not ruminating on the past (Cheng \& Lo, 1991): A young monk and his master met a young lady on a riverside. She was worrying about her inability to get across the river. The master carries her on his back across the river. The young monk is astonished. He asks his master afterwards, "The Buddhist percepts do not allow a monk to have physical contact with the opposite sex. Master, how can you carry a female on your back?" The master replies: "I already let her go. Why are you still carrying her?"

Another story may help a client to accept certain realities in life, such as dying (Narada, 1982). A mother is mourning the death of her son. She begs a Buddhist master to save her son's life. The master says, "I can revive your son only if you can find a family in which nobody has died."

In another story, a young man comes to see a master and asks him, "Can you help me find enlightenment?" The master says, "Bring me your mind. I will enlighten it for you." The man replies, "How can I bring my mind to you? It is nothing!" The master answers, "Then you are enlightened!" 
These stories may help a client become less arrogant and more open to negative experiences (E. Lee, 1997; Yeung, 1995). They may also serve as a heuristic for insight on the meaning of life. Realizing the impermanency of one's physical self by enlightenment on the essential nature of the nonself, a Zen student is urged to be satisfied with what one has at this moment with a peaceful and calm mind.

\section{Research on Effects of Buddhist Technique}

Buddhism presents a worldview that is thoroughly integrated with a discipline of experiential inquiry into the nature of the mind and related phenomena; and it includes empirical, analytical, and religious elements (Segall, 2003). Thus, it can be relevant to philosophical and psychological theory and practice because of its intensive exploration of the mind and its psychological methods to cultivate sustained well-being.

Until recently, psychological theory posited that the set point for experiencing happiness is fixed by temperament and early life experiences and thus is difficult to shift (Kahneman, Diener, \& Schwartz, 1999). However, current psychological research also offers preliminary confirmation of the Buddhist teaching that the degree of one's happiness is not fixed, but instead can be consciously cultivated.

Walsh and Shapiro (2006) proposed a fourfold heuristic model with Buddhism and Western psychology support for well-being, in four ways, to cultivate mental balance: intentionally, attentionally, cognitively, and affectively. Because traditional Buddhist literature does not generally discuss mental health as a topic distinct from teachings about the path to enlightenment, this particular approach is derived from sources in various Buddhist texts that explain how to train the mind in ways that alleviate suffering (Buddhaghosa, 1979; Santideva, 1997; Tsong-kha-pa, 2000, 2002). All schools of Buddhism share in common with Western psychology the fundamental goal to reduce suffering (Bodhi, 2005).

Well-being that transcends transient, stimulus-driven pleasures depends on the cultivation of specific types of enduring beliefs and attitudes and on developing one's signature strengths (Haidt, 2006; Seligman, 2004). The cultivation of meaningful priorities, attitudes, perspectives, and behaviors has been highlighted by positive psychology (Seligman, 1998) and is also strongly emphasized in Buddhist practice (B. A. Wallace, 2001; Santideva, 1997). Both Western psychology and Buddhism claim that happiness, resulting from such internal mental training, is more durable than stimulusdriven pleasures (Brickman \& Campbell, 1971; Ryan \& Deci, 2001). 
Current psychological research on maximizers and satisficers supports this theory of well-being drawn from Buddhism and Western psychology. Maximizers are defined as persons who are always looking for the best, whereas satisficers are satisfied once the threshold of acceptability, based on their intrinsic values, is crossed. Research demonstrates that maximizers' attempts at finding the best paradoxically leads to increased suffering and not increased satisfaction. Of note, although maximizers may achieve better outcomes than satisfiers, they are likely to experience these outcomes as being worse (Iyengar, Wells, \& Schwartz, 2006). As the maximizer attempts to create an ideal internal state through external perfection, dissatisfaction (not pleasure) increases. This reinforces a core hypothesis of Buddhism that expectations and striving after such things as wealth, fame, approval, and power lead to discontentment, anxiety, and frustration.

Current psychological research in affective forecasting finds that people often inaccurately forecast the emotional impact of specific events and therefore make choices based on erroneous calculations of what will bring the greatest happiness (Kahneman et al., 1999). There is substantial evidence for an impact bias in predictions about emotional reactions to future events (for a review, see Wilson \& Gilbert, 2003). These findings lend partial support to the Buddhist view that often what people think will make them happy actually does not lead to lasting well-being.

\section{Conclusion}

The term self-cultivation is used in this article to integrate various culture-sensitive psychotherapies derived from Confucianism, Taoism, and Buddhism. In all of these cultural traditions, the teaching role is important in maintaining the living tradition passed down for generations by word of mouth. In terms of therapy, this teaching role may be partially undertaken by a clinician. In addition, the students, or in this case the clients, should actually try and live their lives according to these principles rather than solely gaining a cognitive understanding of them (Watts, 1961).

Those methods of psychotherapy are essentially different from those of Western counseling psychology, which uses the core technique of confession derived from the tradition of Christianity (Foucault, 1976-1984/1978-1985). A client needs to confess or disclose to the counselor his or her desires, misdeeds, guilt feelings, and psychological disturbances. To change or give up some undesirable aspects of oneself, one first has to face one's "real" self.

For people living in East Asian societies, the traditional one-on-one model of Western counseling is an unnatural way of communicating and conveying 
matters of mutual concern (Gerstein \& Ægisdóttir, 2005). In fact, if an individual confesses or discloses desires, misdeeds, guilt, or psychological disturbances to others in a collectivist or relational society, that individual risks psychosocial imbalance by losing face. On the contrary, once the master learns that the client is suffering from a particulate problem, the master may provide guidelines or instructions to the client for self-cultivation. These guidelines may be teachings or proverbs derived from a religious doctrine. The process might well be described by a popular saying in Chinese societies: The master can only guide you to acquire fundamental principles of a doctrine; to practice them to any extent of expertise is your own business. Similarly, the Sutra of Bodhisttva Precepts also advises followers: "Practice for yourselves the Buddha-praxis, and create for yourselves the Buddha Way."

The goals of self-cultivation are also completely different from that of Western psychotherapy. Instead of using an analytic approach to search for the client's real self, the Asian models encourage the client to find ways for one's social self, authentic self, and nonself. A careful examination over the sociocultural contexts for the development of various methods of psychotherapy reported in this article, namely, Morita therapy for anxiety-based disorders in pre-war Japan, Naikan therapy for the arrangement of interpersonal relationships in Japanese society after World War II, the model of self-relation coordination particularly in Taiwan, Chinese Taoist cognitive psychotherapy in contemporary China, and constructive living in America, it is obvious that the method of cultural adoption may assist a counseling psychologist to develop various techniques of psychotherapy intended to be most appropriate for clients from a particular sociocultural context.

This is a very important lesson for the training program of multicultural counseling in the United States. Models of psychotherapy practiced in other cultural contexts may offer the students of counseling psychology opportunities for intellectual renewal and enable them to have a better understanding of how culture influences behavior (Leong \& Blustein, 2000). They may help a counselor who intends to work in a multicultural community to find the most appropriate technique for his or her clients with a particular culturebound distress. They may also prepare international students to return to their home countries to provide culturally relevant services or develop new techniques of psychotherapy on the grounds of their cultural heritage.

\section{References}

Bell, D., \& Ham, C. (2003). Confucianism for the modern world. New York: Cambridge University Press. 
Bodhi, B. (Ed.). (2005). In Buddha's words: An anthology of discourses from the Pali Canon. Boston: Wisdom.

Brickman, P., \& Campbell, D. T. (1971). Hedonic relativism and planning the good society. In M. H. Appley (Ed.), Adaptation level theory: A symposium (pp. 287-302). San Diego, CA: Academic Press.

Buddhaghosa. (1979). The path of purification (B. Nanamoli, Trans.). Kandy, Sri Lanka: Buddhist Publication Society.

Carrington, P., \& Ephron, H. S. (1976). Meditation as an adjunct to psychotherapy. In S. Arieti \& G. Chraznowski (Eds.), New dimensions in psychiatry (pp. 161-191). New York: John Wiley.

Chen, P. H. (2009). A counseling model for self-relation coordination for Chinese clients with interpersonal conflicts. The Counseling Psychologist, 37, 987-1009.

Cheng, L. Y., \& Lo, H-T. (1991). On the advantages of cross-culture psychotherapy: The minority therapist/mainstream patient dyad. Journal of the Study of Interpersonal Processes, 54, 386-396.

Cohen, K. S. (1997). The way of Qigong: The art and science of Chinese energy healing. New York: Ballantine.

Das, A. K. (1987). Indigenous models of therapy in traditional Asian societies. Journal of Multicultural Counseling and Development, 15, 25-37.

Davidson, R. J., Kabat-Zinn, J., Schumacher, J. Rosenkranz, M., Muller, D., Santorelli, S. F., et al. (2003). Alterations in brain and immune function produced by mindfulness meditation. Psychosomatic Medicine, 65, 564-570.

Deikman, A. J. (1982). The observing self. Boston: Beacon.

De Groot, J. J. M. (1912). Religion in China: Univeralsiam, a key to the study of Taoism and Confucianism. New York: G. P. Putnam.

Doelger, D. K. (1978). A systematic comparison of Gestalt therapy as written by Frederick S. Perls and the philosophy of the Tao Te Ching by Lao Tzu. Dissertation Abstracts International, 39(3-B), 1455.

Epstein, M. (1995). Thoughts without a thinker: Psychotherapy from a Buddhist perspective. New York: Basic Books.

Foucault, M. (1978-1985). The history of sexuality (Vols. 1-2; R. Hurley, Trans.). New York: Vintage. (Original work published 1976-1984)

Fu, C. W., \& Wawrytkoh, S. A. (Eds.). (1991). Buddhist ethics and modern society: An international symposium. Westport, CT: Greenwood.

Fu, C. W., \& Wawrytko, S. A. (Eds.). (1994). Buddhist behavioral codes and modern world: An international symposium. Westport, CT: Greenwood.

Gerstein, L. H., \& Ægisdóttir, S. (2005). A trip around the world: A counseling travelogue. Journal of Mental Health Counseling, 27, 95-103.

Gielen, U. P., Jefferson, M. F., \& Juris, G. D. (2004). Handbook of culture, therapy, and healing. Mahwah, NJ: Lawrence Erlbam.

Goleman, D. (1977). The variety of meditative experience. New York: John Wiley.

Hahn, T. N. (1992). Peace is every step. New York: Bantam Books.

Haidt, J. (2006). The Happiness hypothesis: Finding modern truth in ancient wisdom. New York: Basic Books.

Heppner, P. P. (2006). The benefits and challenges of becoming cross-culturally competent counseling psychologists: Presidential address. The Counseling Psychologist, 34, 147-172.

Hranilovich, T. E. (1991). Applications of the "Tao-te-Ching" of Lao Tzu to psychotherapy theory and technique. Dissertation Abstracts International, 51(12-B, Pt. 1), 6106.

Hsu, F. L. K. (1971). Psychological homeostasis and jen: Conceptual tools for advancing psychological anthropology. American Anthropologist, 73, 23-44. 
Hwang, K. K. (1999). Filial piety and loyalty: Two types of social identification in Confucianism. Asian Journal of Social Psychology, 2, 163-183.

Hwang, K. K. (2001a). The deep structure of Confucianism: A social psychological approach. Asian Philosophy, 11, 179-204.

Hwang, K. K. (2001b). Morality: East and West. In N. J. Smelser (Ed.), International encyclopedia of the social and behavior science (pp. 10039-10043). Elmsford, NY: Pergamon.

Iwai, H., \& Abe, T. (1975). Morita ryoho no riron to jissai [Theory and practice of Morita Therapy]. Tokyo: Kongo Shuppan.

Iyengar, S., Wells, R., \& Schwartz, B. (2006). Doing better but feeling worse: Looking for the "best" job undermines satisfaction. Psychological Science, 17, 143-150.

Johanson, G., \& Kurtz, R. (1991). Grace unfolding: Psychotherapy in the spirit of the Tao-te Ching. New York: Bell Tower.

Kahneman, D., Diener, E., \& Schwarz, N. (Eds.). (1999). Well-being: The foundations of hedonic psychology. New York: Russell Sage.

Kerr, C. (2002). Translating "mind-in-body": Two models of patient experience underlying a randomized controlled trial of Qigong. Culture, Medicine, \& Psychiatry, 26, 419-448.

Kershaw, S. (2003, January 18). Freud meets Buddha: Therapy for immigrants. The New York Times, pp. B1, 2c.

Kimura, B. (1972). Hito to Hito tono Aida [Interpersonal space]. Tokyo: Kobundo.

Kohn, L. (2004). Daoism and Chinese culture (2nd ed.). Cambridge, UK: Three Pines Press.

Kutz, I., Borysenko, J. Z., \& Benson, H. (1985). Meditation and psychotherapy: A rationale for the integration of dynamic psychotherapy, the relaxation response, and mindfulness meditation, American Journal of Psychiatry, 142, 1-8.

Lee, E. (1997). Working with Asian Americans: A guide for clinicians. New York: Guilford.

Lee, S., \& Kleinman, A. (1997). Mental illness and social change in China. Harvard Review of Psychiatry, 5, 43-46.

Leong, F. T. L., \& Blustein, D. L. (2000). Toward a global vision of counseling psychology. The Counseling Psychologist, 28, 5-9.

Lu, K. Y. (1964). The secrets of Chinese meditation. London: Rider.

Lu, T. P. (1962). The secret of the golden flower A Chinese book of life (R. Wilhelm, Trans.). New York: Harcourt, Brace World.

Markus, H. R., \& Kitayama, S. (1991). Culture and the self: Implications for cognition, emotion and motivation. Psychological Review, 98, 224-253.

Morita, S. (1998). Morita therapy and the true nature of anxiety-based disorders (Shinkeishitsu) (P. LeVine, Ed., A. Kondo, Trans.). Albany: State University of New York Press. (Original work published 1928)

Munro, D. J. (1985). Individualism and holism: Studies in Confucian and Taoist values. Ann Arbor: Center for Chinese Studies, University of Michigan.

Murase, T., \& Johnson, F. A. (1974). Naikan, Morita, and Western psychotherapy: A comparison. Archives of General Psychiatry, 31, 121-128.

Narada, M. T. (1982). The Buddha and his teachings. Singapore: Buddhist Meditation Center.

Ni, H. C. (1992). Internal alchemy: The natural way to immortality. Santa Monica, CA: College of Tao and Traditional Chinese Healing.

Ornstein, R. E. (1972). The psychology of consciousness. San Francisco: Freeman.

Rahula, W. (1973). "Meditation" or mental culture. In R. E. Ornstein (Ed.), The nature of human consciousness (pp. 242-248). San Francisco: Freeman.

Reynolds, D. K. (1976). Morita psychotherapy. Berkeley: University of California Press.

Reynolds, D. K. (1980). The quiet therapies. Honolulu: University of Hawaii Press. 
Reynolds, D. K. (1983). Naikan psychotherapy. Chicago: University of Chicago Press.

Reynolds, D. K. (1987). Water bears no scars. New York: William Morrow

Reynolds, D. K. (1989a). Flowing Bridges and Quiet Waters: Japanese Psychotherapies, Morita and Naikan. New York: SUNY Press.

Reynolds, D. K. (1989b). Meaningful life therapy. Culture, Medicine, \& Psychiatry, 13, 457-463.

Reynolds, D. K. (1990). A thousand waves. New York: William Morrow.

Reynolds, D. K. (1995). A handbook for constructive living. Honolulu: University Press of Hawaii.

Ryan, R. M., \& Deci, E. L. (2001). On happiness and human potentials: A review of research on hedonic and eudaimonic well-being. Annual Review of Psychology, 52, 141-166.

Sampson, E. E. (1988). The debate on individualism: Indigenous psychology of the individual and their role in personal and societal functioning. American Psychologist, 1, 15-22.

Sato, K. (1968). Zen from a personological viewpoint. Psychologica, 11, 3-24.

Segall, S. R. (Ed.). (2003). Encountering Buddhism: Western psychology and Buddhist teachings. Albany: State University of New York Press.

Seligman, M. (1998). Learned optimism. New York: Pocket Books.

Seligman, M. (2004). Authentic happiness: Using the new positive psychology to realize your potential for lasting fulfillment. New York: Free Press.

Seligman, M., \& Csikszentmihalyi, M. (2000). Positive psychology: An introduction. American Psychologist, 55, 5-14.

Santideva. (1997). A guide to the Bodhisattva way of life (V. A. Wallace \& B. A. Wallace, Trans.). Ithaca, NY: Snow Lion.

Smith, H. (1991). The world's religions. San Francisco: Harper \& Row.

Spear, W. (1995). Feng Shui made easy. San Francisco: Harper \& Row.

Tsong-kha-pa. (2000). The great treatise on the stages of the path to enlightenment (Vol. 1). Ithaca, NY: Snow Lion.

Tsong-kha-pa. (2002). The great treatise on the stages of the path to enlightenment (Vol. 3). Ithaca, NY: Snow Lion.

Tu, W. M. (1976). Neo-Confucian thought in action-Wang Yang-Ming's youth (1472-1509). Los Angeles: University of California Press.

Vygotskii, L. S. (1978). Mind in society: The development of higher psychological processes. Cambridge, MA: Harvard University Press.

Wallace, B. A. (2001). Buddhism with an attitude: The Tibetan seven-point mind-training. Ithaca, NY: Snow Lion.

Wallace, R. K., \& Benson, H. (1972, February). The physiology of meditation. Scientific American, 226, 84-90.

Walsh, R., \& Shapiro, S. L. (2006). The meeting of meditative disciplines and Western psychology: A mutually enriching dialogue. American Psychologist, 61, 227-239.

Watts, A. (1961). Psychotherapy East and West. New York: New American Library.

Wilhelm, R. (1960). The I Ching or book of changes (C. F. Baynes, Trans.). London: Routledge \& Kegan Paul.

Williamson, M. (1992). The technique of self-psychological therapy and the Tao. Australian Journal of Psychotherapy, 11, 79-96.

Wilson, T., \& Gilbert, D. (2003). Affective forecasting. In M. P. Zanna (Ed.). Advances in experimental social psychology (Vol. 35, pp. 345-411). San Diego, CA: Academic Press.

Wong, E. (1996). Feng-shui: The ancient wisdom of harmonious living for modern times. Boston: Shambhala Publications. 
Yeung, W. H. (1995). Buddhism, death and dying. In J. K. Parry \& A. Shen Ryan (Eds.), A cross-cultural look at death, dying, and religion (pp. 193-214). Chicago: Nelson Hall.

Zhang, Y. L. (1993). Comparison of coping styles after stress between patients with mental disorders and normal controls. Chinese Journal of Clinical Psychology, 1, 36-39.

Zhang, Y., Young, D., Lee, S., Li, L., Zhang, H., Xiao, Z., et al. (2002). Chinese Taoist cognitive psychotherapy in the treatment of generalized anxiety disorder in contemporary China. Transcultural Psychiatry, 39, 115-130.

Kwang-Kuo Hwang obtained his $\mathrm{PhD}$ in social psychology at the University of Hawaii. He is currently National Chair Professor at National Taiwan University awarded by Taiwan's Ministry of Education, and National Policy Advisor to the President. He has endeavored to promote the indigenization movement of psychology and social science in Chinese society since the early 1980s, and has published eight books and more than one hundred articles on related issues in both Chinese and English. He is past president of the Asian Association of Social Psychology (2003-2005), and was Principal Investigator of In search of excellence for indigenous psychological research project sponsored by the Ministry of Education, R.O.C. (2000-2008).

Jeffrey Chang is a passionate and deeply committed student and contributor within international psychology. At McGill University, he solidified his foundation and philosophical approach in applied social cultural identity research. At Ohio State University, he conducted graduate research on the cultural implications of the counseling and psychology fields. The cultural implications from his research reinforced his pre-graduate and graduate work with the international and clinical populations. At Columbia University, Teacher's College, Dr. Chang decided to persue graduate training in industrial organizational psychology and investigate the implications of the situational context and social-cultural perspectives on working employees. Dr. Chang now applies his foundation in international, social cultural and counseling psychology to the working community, including those employees in higher education. 